\title{
Where Restoration Emerged: A Gem of a Reserve Celebrates Its Diamond Anniversary
}

F rom its beginning, the UW-Madison Arboretum has focused on restoring plant and animal communities native to Wisconsin. Following Aldo Leopold's 1934 dedication of an initial parcel of land for research and teaching, UW faculty and students began testing how best to turn a horse pasture into what is now Curtis Prairie-an icon for prairie restoration worldwide. The Arboretum is bigger now and faced with more challenges, many of which are familiar to managers of natural areas elsewhere. The remnant, restored, and degraded ecosystems on Arboretum property in Madison (480 ha) and 11 outlying areas (205 ha) are increasingly subject to invasive species, urban stormwater inflows, constraints on controlled burning, and changing climate. In Madison, 184 ha of the Arboretum land has not been restored. Which experimental approaches should be tested to restore biota that can thrive in tomorrow's novel conditions?

To celebrate the Arboretum's 75-year legacy of sciencebased land conservation and restoration, UW students are participating in a graduate seminar that examines the development of key concepts in restoration ecology over the past 75 years and looks forward to the innovations needed to advance the science over the next 75 years. We are reaching out to scientists whose expertise can help shape the future of Arboretum research and practice. Our seminar is engaging a dozen guests from around the country who will share their experiences and help us look back and also forward. Our first two guests, Jeb Barzen, Field Ecology Director at the International Crane Foundation, and Jack Ewel, Emeritus Ecologist, University of Florida, shared their thoughts with us this past February. Future seminar guests, many of them joining us electronically, include Roger Anderson, Sara Baer, Curt Meine, Mary Jean Huston, Jon Chipman, Evan Weiher, Richard Hobbs, Tom Givnish, Sara Hotchkiss, and William R. Jordan III.

Jeb Barzen reported his findings that restoration outcomes depend in part on the initial conditions, and that few have explored the effect of "year." Working at the International Crane Foundation near Baraboo, Wisconsin, Barzen held constant the site conditions, seed mix, and

Ecological Restoration Vol. 27, No. 2, 2009

ISSN 1522-4740 E-ISSN 1543-4079

(C2009 by the Board of Regents of the University of Wisconsin System. annual burning, but varied the year by planting five prairies between 1990 and 1996. Each received 1,000 seeds/ $\mathrm{m}^{2}$ from 11 grass and 59 forb species. His 17 -year study revealed unique pathways and outcomes for each prairie both in the species that became dominant and how their cover changed over time. Diversity was initially 60-95 species per site, based on $0.25-\mathrm{m}^{2}$ samples along transects, but it decreased over the study period to 55-80 species. Changes were still occurring after 17 years, although the rate of change slowed. Barzen suggested that a single weather extreme could determine dominance for decades, although the exact causes of different outcomes are uncertain. Given high variability in initial and current composition, Barzen found it difficult to say when restoration will be "finished," but he argued for long-term monitoring to track spatial and temporal dynamics. Barzen suggested that the science of prairie restoration is well developed, but that greater effort is needed to engage private landowners in ecological restoration, especially involving large areas and long-term projects.

Jack Ewel suggested the need to consider four critical questions in planning restoration: When should the existing state be "tweaked" versus replaced; when should alien species be accommodated; when should novel ecosystems be created; and when should we implement projects in anticipation of future conditions? Alien species are often avoided, but recent case studies indicate how they can play critical roles that complement native species. Discussing an example from Hawaii, Ewel wondered if an alien grass- and tree-fern-dominated site that was churned up and planted to Acacia koa would have developed into the desired forest on its own, given sufficient time. Restorationists might need to more patient. In the Florida Everglades, rockplowed soils became dominated by Brazilian pepper trees after agricultural abandonment. Ewel noted that the novel woody vegetation supported endangered panthers, but not after trees were removed to restore sawgrass. Restoration of native plants might come at the cost of restoring valued animals. He shared a third example that illustrated how an alien species could be harnessed to restore Hawaiian hillsides that had been logged, eroded, and kept bare by firewood collectors. The careful selection of a fig tree with poor quality wood did not tempt local people to harvest the planted trees. Thus, the trees survived to produce fruit, 
which led to a sustainable system that effectively controlled erosion. In anticipation of challenges presented by climate change, Ewel discussed the need to plant trees above current treelines where warming climate is eliminating critical bird habitat on one Hawaiian mountaintop. Ewel suggested that while restoration typically aims to mimic yesterday's reference ecosystems, planners need to consider tomorrow's novel environmental conditions, which might require novel assemblages of species. His conceptual model recommends that the more disturbed (harsh) the site and the fewer native features it retains, and the less complex the ecosystem, the more latitude there is for employing (non-invasive) alien species.

Both guest scientists addressed topics that are of great concern to the Arboretum. We do not know when our prairie restorations will be "done," and we are uncertain how best to restore new habitats to endure future environmental conditions. Our 75 years of effort devoted to restoring Curtis Prairie indicate that experimental approaches are still needed. Prairie attributes are increasingly threatened by succession from grassland toward shrub dominance, despite annual burning. The most guilty shrub is a native species, Cornus racemosa (gray dogwood). As the shrub expands in area and increases in cover, native plant species occurrences diminish, as does the grassy biomass that is needed to carry a hot fire. Like the alternative states described for Australian shrubland and pasture in a new book by Richard J. Hobbs and Katharine N. Suding, New Models for Ecosystem Dynamics and Restoration, it seems there are strong feedback mechanisms that sustain the shrubs in the Arboretum where people prefer prairie. The experimental tradition needs to be continued within an adaptive restoration framework, not only to improve restoration of native species, but also to provide self-sustaining ecosystems that can meet the challenges of a changing environment.

Joy B. Zedler, Aldo Leopold Chair of Restoration Ecology University of Wisconsin Arboretum, Madison

\section{Reference}

Hobbs R.J. and K.N. Suding. 2008. New Models for Ecosystem Dynamics and Restoration. Washington DC: Island Press. 